\title{
autêntica
}

\author{
ARTIGOS
}

\section{Os movimentos reflexivos presentes nas pesquisas do núcleo UFMS no projeto em rede observatório da educação}

Patrícia Sândalo Pereira

\begin{abstract}
RESUMO
Este artigo traz alguns resultados das primeiras pesquisas desenvolvidas no Núcleo UFMS vinculadas ao projeto de pesquisa em rede, aprovado no Edital 049/2012, do Programa Observatório da Educação da Capes, intitulado "Trabalho colaborativo com professores que ensinam Matemática na Educação Básica em escolas públicas das regiões Nordeste e Centro-Oeste". As pesquisas utilizaram, como referenciais teóricos e metodológicos, os pressupostos da pesquisa colaborativa, fundamentados em Desgagné (2007) e Ibiapina (2008). A pesquisa colaborativa diferencia-se de outras metodologias pelo seu caráter participativo, colaborativo e reflexivo, ou seja, tem uma dupla identidade: a pesquisa e a formação. Os resultados apontados nas pesquisas evidenciaram que a ação conjunta entre pesquisadores e professores da Educação Básica possibilitou movimentos participativos, colaborativos e reflexivos, possibilitando aos professores explorar e questionar os seus próprios saberes e práticas, além de propiciar o enfrentamento e a superação das necessidades apresentadas no desenvolvimento de suas práticas docentes.
\end{abstract}

\section{PALAVRAS-CHAVE}

Formação Continuada; Observatório da Educação; Pesquisa Colaborativa.

THE REFLECTIVE MOVES PRESENTED IN THE RESEARCHES OF THE CORE OF UFMS IN THE NETWORK PROJECT OBSERVATORY OF EDUCATION

\begin{abstract}
This article brings some results of the first researches developed in the Core of UFMS, they are linked in the project of research in network, aproved in the notice 049/2012, of the Program Observatory of Education of CAPES, titled "collaborative work with professors that teach Math in the basic education in public schools of the northeast and midwest."The researches use as theorethical and metodological frameworks the premises of the collaborative research, founded by Desgagné (2007) and Ibiapina (2008). The collaborative research differs from other metodologies for its participatory nature, collaborative and reflective, i. e., has a double identity: the research and the formation. The results obtained in the researches revealed the conjunct action between researchers and professors of the basic education allowed participative moves, collaboratives and reflexives, allowing professors explore and question their own knowledges and practices, as well as provide the confrontation and overcoming of the presented necessities in the development of their teaching practices.
\end{abstract}

\section{KEYWORDS}

Continuous Formantion; Observatory of Education; Collaborative Research 


\section{autêntica}

\section{INTRODUÇÃO}

O movimento formativo do sujeito a partir da realidade objetiva é um caminho que possibilita inúmeras reflexões. Um caminho que tem se evidenciado de forma a amenizar o abismo inerente entre a formação inicial, formação continuada, extensão e formação em pesquisa e divulgação científica é o da política de formação e desenvolvimento profissional de professores da rede pública, no qual nasce o Programa Observatório da Educação (OBEDUC). Esse Programa foi instituído pelo Decreto Presidencial n ${ }^{\circ} 5.803$, de 08 de junho de 2006, resultado da parceria entre a Coordenação de Aperfeiçoamento de Pessoal de Nível Superior - CAPES e do Instituto Nacional de Estudos e Pesquisas Educacionais Anísio Teixeira - INEP, com a finalidade de fomentar a produção acadêmica e a formação de recursos pós-graduados em educação, em nível de mestrado e doutorado, por meio de financiamento específico'. Um ponto importante a ser ressaltado nesse Programa é a união de acadêmicos de graduação e de pós-graduação juntamente com os professores da Educação Básica e pesquisadores para juntos desenvolverem pesquisas.

Reafirmando essa importância, em 2013, durante o $4^{\circ}$ Seminário do Programa Observatório da Educação (OBEDUC), a Diretora de Formação de Professores da Educação Básica - Carmen Moreira de Castro Neves explicitou o foco a ser sustentado pela Capes: Queremos ter na Capes uma política de estado de formação de professores sólida, que englobe formação inicial; formação continuada e extensão e formação em pesquisa e divulgação científica'.

Dentro dessa perspectiva, temos que a formação continuada tem sido um importante instrumento de políticas públicas do Governo e as instituições de ensino superior têm se engajado na articulação com a Educação Básica no sentido evidenciado por Zeichner (2010). Esse autor, ao referir-se sobre o aperfeiçoamento dos sujeitos afirma que

[...] a criação de espaços híbridos na formação de professores no qual o conhecimento empírico e acadêmico e o conhecimento que existe nas comunidades estão juntos de modo menos hierárquicos a serviço da aprendizagem docente (ZEICHNER, 2010, p. 479).

Nesse viés, a partir dessas parcerias, foi desenvolvido o projeto em rede intitulado "Trabalho colaborativo com professores que ensinam Matemática na Educação Básica em escolas públicas das regiões Nordeste e Centro-Oeste," que foi aprovado no Edital 049/2012 do Programa Observatório da Educação - OBEDUC - CAPES e tem como objetivo propiciar, por meio de práticas colaborativas, a reflexão desses professores acerca do trabalho didático/pedagógico e desencadear ações educativas voltadas para a sala de aula.

Este projeto contou com a participação de três Universidades: Universidade Federal do Mato Grosso do Sul (UFMS - instituição sede), Universidade Estadual da Paraíba (UEPB) e Universidade Federal de Alagoas (UFAL), com um total de 46 integrantes entre doutores, doutorandos, mestres, mestrandos, licenciandos em Matemática e Pedagogia e professores da Educação Básica de Matemática.

Neste artigo, relataremos o caminhar das pesquisas atreladas ao grupo de pesquisa FORMEM - Formação e Educação Matemática que foram desenvolvidas no projeto OBEDUC no Núcleo UFMS, em particular, duas dissertações de mestrado que foram concluídas no período, são elas: Pardim (2015) e Jorge (2015).

\section{O MOVIMENTO DE PESQUISA E A FORMAÇÃO NO PROJETO OBEDUC}

Na perspectiva de minimizar as lacunas inerentes à formação docente, nas últimas décadas, algumas políticas públicas educacionais foram implantadas pelo governo federal, o qual lançou várias ações visando atender tanto a demanda de formação inicial, em nível superior exigida por Lei, quanto à formação continuada. 


\section{autêntica}

Gatti (2003) aborda o conceito de formação docente como sendo um processo histórico e socialmente construído, o que implica necessariamente considerar o professor como um sujeito imbuído de realidades objetivas, "em função de complexos processos não apenas cognitivos, mas, socioafetivo e culturais". (GATTI, 2003, p. 192).

Essa autora afirma que,

[...] é preciso ver os professores não como seres abstratos, ou essencialmente intelectuais, mas, como seres essencialmente sociais, com suas identidades pessoais e profissionais, imersos numa vida grupal na qual partilham uma cultura, derivando seus conhecimentos, valores e atitudes dessas relações, com base nas representações constituídas nesse processo que é, ao mesmo tempo, social e intersubjetivo. (GATTI, 2003, p. 196)

Ao tratarmos especificamente da formação continuada de professores, cabe ressaltar que muitas políticas voltadas a essa formação têm se mostrado ineficazes, pois, segundo Gatti (2003), as suas ações não têm considerado o fato de que os professores "são pessoas integradas a grupos sociais de referência nos quais se gestam concepções de educação, de modos de ser, que se constituem em representações e valores que filtram os conhecimentos que Ihes chegam" (GATTI, 2003, p. 192). Logo, ao desconsiderar esses fatores, tem-se uma concepção limitada de que:

[...] o aumento e a melhoria do rol de conhecimentos informativos, adquiridos individualmente, será suficiente para melhorar ou modificar conceitos e práticas ligados ao trabalho profissional de professores. (GATTI, 2003, p. 196)

Corroborando com essa discussão, Nóvoa (1995) afirma que

[...] a formação não se constrói por acumulação (de cursos, de conhecimentos ou de técnicas), mas sim através de um trabalho de reflexividade crítica sobre as práticas e de (re)construção permanente de uma identidade pessoal. Por isso é tão importante investir na pessoa e dar um estatuto ao saber da experiência (NÓVOA, 1995, p. 25).

Nessa perspectiva, a prática docente objetiva dos professores ganharia status de objeto de estudo, partindo sempre da necessidade do sujeito, na busca da prática ontológica, buscando compreender a sua origem, a sua natureza e, por fim, a sua verdadeira função.

Nessa tentativa, podemos observar que muitas pesquisas voltadas para a formação continuada de professores têm se pautado em programas que privilegiam a parceria entre escolas e universidades. Essas pesquisas desenvolvem ações conjuntas, buscando atender as necessidades do docente em seu lócus de atuação profissional: a sala de aula, viabilizando a constituição de espaços formativos que valorizam a reflexão desses professores acerca da sua prática. Pesquisadores como Ponte (1995), Ferreira (2003) e Sousa (2013), dentre outros, têm defendido essas parcerias, propondo a constituição de grupos de trabalho dentro das escolas. Esses pesquisadores veem a escola e o trabalho colaborativo como instâncias do desenvolvimento dos professores, por proporcionarem condições de formação permanente, compartilhamento de experiências e busca de soluções para os problemas que emergem do contexto escolar.

Neste sentido, iniciativas educacionais mais recentes têm aliado em um mesmo projeto, pesquisa e formação, como é o caso do Projeto OBEDUC, que foi desenvolvido no Núcleo UFMS. 


\section{autêntica}

Desgagné (2007) esclarece-nos que um projeto de pesquisa colaborativa não apenas constrói-se sobre uma dupla identidade, pesquisa e formação, mas também que essas dimensões podem ser conduzidas em paralelo, como explicita:

Decerto, partindo do pivô central que constitui a démarche de reflexão conjunta, ou de co-construção, realizada pela interação entre pesquisador e docentes, o projeto vai se articular de duas formas: a) como um projeto de aperfeiçoamento para os docentes que desejarem questionar ou explorar um aspecto de sua prática profissional; b) como um projeto de pesquisa, cujo objeto se constitui numa preocupação para o pesquisador. (DESGAGNÉ, 2007, p. 15)

Segundo o autor, essa dupla identidade é exigência do próprio conceito de colaboração, pois, esse conceito supõe a possibilidade de interação e engajamento de cada partícipe a partir das suas preocupações, das suas necessidades e dos seus respectivos interesses. Portanto, no interior desse processo de reflexão e de compreensão acerca de uma determinada situação prática, a pesquisa colaborativa supõe a co-construção de um objeto de conhecimento entre pesquisador e docentes.

Um ponto importante a ser destacado é que a pesquisa colaborativa desenvolve-se mediante uma parceria entre as instituições e as relações pessoais em torno de um objetivo comum.

A pesquisa colaborativa, segundo Ibiapina (2008), é uma abordagem de pesquisa que alia investigação e formação em processos de compreensão, interpretação e transformação de realidades sociais. A autora, em concordância com Desgagné (2007), reafirma que a ideia da colaboração, na construção de conhecimentos entre pesquisadores e professores ligados às práticas de ensino, surge a partir da constatação de um distanciamento entre o mundo da pesquisa e o mundo da prática. E isso decorre do fosso existente entre universidade e escola, entre teoria e prática. A autora enfatiza que

[...] os conhecimentos construídos sobre a prática, sob a responsabilidade das universidades e de suas faculdades de educação, não são transpostos para a escola, não ajudando, assim, os professores a melhor enfrentar a complexidade das situações educativas que eles se confrontam cotidianamente. (IBIAPINA, 2008, p. 15).

Portanto, dessa constatação, podemos evocar a importância da abordagem colaborativa no campo da educação, pois, para que ela efetive-se, o professor da escola necessita "estar junto", negociando sentidos e significados. Neste sentido, a pesquisa colaborativa contribui para o processo de produção de conhecimentos e para a formação de professores, objetivando a transformação das realidades concretas educacionais.

A consequência de tal perspectiva de pesquisa é que o projeto de colaboração põe o pesquisador em situação de co-construção com os docentes, podendo ser visto, simultaneamente, como uma atividade de pesquisa e de formação. Com efeito, aliar-se aos professores para co-construir um objeto de conhecimento é também fazê-los entrar em um processo de aperfeiçoamento.

\section{O CAMINHAR DAS PESQUISAS DO NÚCLEO UFMS NO PROJETO OBEDUC}

Inicialmente, no projeto OBEDUC, estava prevista, para o Núcleo UFMS, a participação de dezesseis integrantes, sendo quatro mestrandos, sete professores da Educação Básica, quatro acadêmicos de Matemática e a coordenadora institucional. Mas, diante da impossibilidade de ter-se quatro orientandos de mestrado no 


\section{autêntica}

mesmo ano, a inserção ocorreu da seguinte maneira: um mestrando no primeiro ano, dois, no segundo ano e um, no terceiro ano.

Desde o início do projeto em 2013, no Núcleo UFMS, todos os integrantes participavam juntos e partíamos de uma perspectiva colaborativa, conforme estabelecido no projeto OBEDUC que foi aprovado.

Para a realização deste projeto de cunho investigativo qualitativo, primeiramente, estabelecemos uma parceria com os professores da Educação Básica. Sendo assim, assumimos como estratégia metodológica a constituição de um grupo de trabalho colaborativo. Nesse tipo de trabalho,

[...] os formadores e professores podem, colaborativamente, elaborar tarefas de ensino ou analisar episódios de aulas, os quais podem ser registrados em vídeos ou narrados pelos próprios participantes. (FIORENTINI, 2013b, p. 3).

Nas reuniões desenvolvidas no grupo, os problemas eram trazidos e discutidos pelos professores. A busca de literatura era realizada por todos do grupo. Partindo das leituras, eram planejadas algumas tarefas e ações a serem desenvolvidas na escola. Os professores registravam as informações e as impressões que tiveram acerca da aplicação das atividades desenvolvidas em sala de aula e traziam para o grupo.

Os encontros eram realizados quinzenalmente na sala do Laboratório do Grupo de Pesquisa FORMEM Formação e Educação Matemática -, na unidade VII da Universidade Federal do Mato Grosso do Sul. Esses encontros colaborativos oportunizaram aos integrantes do grupo compartilhar um pouco de si, acreditar em si e perceberem que a interação possibilitava discutir as suas necessidades.

Segundo Ibiapina (2008),

[...] investigadores e professores tanto em processos de produção de conhecimentos, quanto de desenvolvimento interativo da própria pesquisa, haja vista que o trabalho colaborativo faz com que professores e pesquisadores produzam saberes, compartilhando estratégias que promovem desenvolvimento profissional. Nessa perspectiva, é atividade de coprodução de conhecimentos e de formação em que os pares colaboram entre si com o objetivo de resolver conjuntamente problemas que afligem a educação (IBIAPINA, 2008, p. 25).

Nesse viés, tem sido realizado um trabalho colaborativo no grupo, possibilitando aos integrantes uma formação continuada para a melhoria das suas práticas pedagógicas e profissionais. Espaços de formação de trabalho conjunto, entre professores da Educação Básica, mestrandos e licenciandos proporcionam aos futuros professores socializações com os alunos da Educação Básica e com professores mais bem preparados e motivados. Tudo isso contribui para o início de seu percurso profissional, pois, já vivenciou o convívio da comunidade escolar. Também, nesse contexto, as angústias e as incertezas são partilhadas e discutidas, buscando-se ajuda e apoio mútuo, de modo que esse empenho conjunto possa levar os alunos ao sucesso no seu aprendizado.

Para desenvolver esses trabalhos, foi estabelecida uma relação de respeito, confiança e diálogo, com o intuito de conduzir cada participante a conversar, negociar e analisar as situações envolvidas na comunidade escolar.

Ibiapina (2008) evidencia a virtude do pesquisador ao atuar em dois campos, o da pesquisa e o da formação. A autora esclarece que é o processo de investigação na ação que possibilita a reflexão e a colaboração entre 


\section{DOCENTE}

autêntica

as participantes e a pesquisadora. Logo, com essa ênfase, as possibilidades de reflexão de cada integrante são de grande importância para análise do grupo, pois demonstram as diversas formas da postura reflexiva profissional, compreendendo as ideias e as atitudes adquiridas no decorrer da formação do grupo, visando à emancipação, possibilitando, assim, uma valorização intelectual.

Já, a partir de 2014, com a entrada de mais dois mestrandos, os integrantes foram divididos em subgrupos. Cada subgrupo foi composto pelo pesquisador, pela orientadora, pelo professor da rede estadual de ensino e pelos alunos de graduação em Matemática, de modo a potencializar nossas ações de trabalho.

Nos subgrupos, os pesquisadores podiam realizar as atividades de pesquisa, pois o objetivo em comum que mobilizava esses subgrupos era apenas um. Seria diferente se as ações fossem realizadas no grupo geral, onde haveria vários objetivos comuns e várias questões. Ressaltamos que a formação dos subgrupos não foi para romper com o grupo geral, haja vista que os subgrupos reuniam-se uma vez por mês para dialogarem sobre as ações e compartilharem as suas experiências.

Em 2015, tivemos o ingresso de mais um mestrando e uma doutoranda, além do que já estava previsto no projeto. Isso ocorreu devido à oferta de duas vagas para o mestrado e da aprovação do Doutorado em Educação Matemática, onde havia uma vaga sob minha orientação.

\section{AS PRIMEIRAS PESQUISAS DESENVOLVIDAS NO NÚCLEO UFMS}

Após o início do projeto OBEDUC em 2013, o Núcleo UFMS teve duas dissertações de mestrado defendidas, são elas: Pardim (2015) e Jorge (2015), conforme apresentada na Tabela 1 a seguir.

TABELA 1 - AS PRIMEIRAS PESQUISAS DESENVOLVIDAS NO PROJETO OBEDUC - NÚCLEO UFMS

\begin{tabular}{c|c|c} 
AUTOR / ANO & TítUlo & PALAVRAS-CHAVE \\
Pardim & $\begin{array}{c}\text { Reflexões e interações de um } \\
\text { professor da Educação Básica } \\
\text { em um projeto colaborativo }\end{array}$ & $\begin{array}{c}\text { Educação Matemática, } \\
\text { Observatório da Educação, Formação } \\
\text { Continuada de Professores, } \\
\text { Colaboração. }\end{array}$ \\
\hline Jorge & $\begin{array}{c}\text { Reflexões sobre a prática } \\
\text { docente de um professor de } \\
\text { Matemática a partir da Pesquisa } \\
\text { Colaborativa }\end{array}$ & $\begin{array}{c}\text { Formação Continuada, Reflexão, } \\
\text { Espiral Reflexiva Ampliada, } \\
\text { Observatório da Educação. }\end{array}$ \\
\hline
\end{tabular}

Fonte: Arquivo do grupo de pesquisa FORMEM.

A pesquisa de Pardim (2015) teve como objetivo analisar os movimentos reflexivos de um professor acerca da sua prática, quando participa de ciclos de estudos colaborativos, visando responder à seguinte questão: Como a participação de um professor em ciclos de estudos colaborativos pode levá-lo a movimentos reflexivos sobre a sua prática? 
O referencial teórico foi baseado nos seguintes autores: Fiorentini (2008, 2009, 2013a), Ibiapina (2008), Boavida e Ponte (2002), Zeichner (1993, 2008) e Alarcão (2003).

No ano de 2014, buscando as reflexões do professor sobre a sua prática, a pesquisa foi desenvolvida em uma escola municipal em duas turmas de sexto ano do Ensino Fundamental. Como procedimentos metodológicos, foram utilizados os ciclos de estudos colaborativos, os registros reflexivos, as entrevistas narrativas, a autobiografia e as transcrições dos vídeos das reuniões do grupo e subgrupo.

A pesquisa de Jorge (2015) teve como objetivo compreender o processo reflexivo de um professor de Matemática sobre a sua prática docente no âmbito de sala de aula, a partir da pesquisa colaborativa, visando responder a seguinte questão: Como a pesquisa colaborativa possibilita compreender o processo reflexivo de um professor de Matemática sobre a sua prática docente a partir da espiral reflexiva ampliada?

A pesquisa foi desenvolvida em uma Escola Estadual na sala de aula de um professor no primeiro ano do Ensino Médio. Como instrumentos para coleta de dados, foram utilizados os passos da espiral reflexiva propostos por Ibiapina (2008), são eles: planejamento, aplicação da aula, entrevista e sessão reflexiva. Porém, ampliamos essa espiral, inserindo três novos passos, tais como: novo planejamento, nova aplicação da aula e nova entrevista.

As duas pesquisas de Pardim (2015) e Jorge (2015) tiveram como referencial teórico e metodológico a pesquisa colaborativa (IBIAPINA, 2008), que busca fortalecer o diálogo entre a universidade e a escola, possibilitando aos professores da Educação Básica repensar as suas práticas pedagógicas nas aulas de Matemática. Além disso, as duas pesquisas buscaram os movimentos reflexivos dos professores de Educação Básica de Matemática.

\section{ALGUNS RESULTADOS}

Apresentamos, a seguir, alguns resultados encontrados nas pesquisas de Pardim (2015) e Jorge (2015).

As análises da pesquisa de Pardim (2015) foram pautadas nas reflexões de um professor da Educação Básica e nas falas dos integrantes do subgrupo e do grupo no Núcleo UFMS, com o objetivo de identificar as interações de um professor em um grupo colaborativo e identificar os movimentos reflexivos do professor.

No primeiro encontro, foi apresentado o projeto aos participantes e ressaltado que os encontros seriam momentos em que todos os integrantes do grupo deveriam explorar e questionar os seus próprios saberes e práticas, de modo a estabelecer relações e buscar compreensões no confronto com os saberes e com as práticas dos outros. Também foi enfatizada a proposição de horizontalidade científica e a proposta de que todos se colocassem no mesmo patamar sem estabelecimento de hierarquias. Para Magalhães e Oliveira (2011, p. 69), a colaboração "é marcada pelo trabalho conjunto, pelo apoio mútuo, pela definição coletiva de motivos comuns, e, sendo assim, as ações não são hierárquicas." Neste sentido, mesmo que os integrantes tenham atribuições e perspectiva de participações diversas, elas são evidenciadas e empreendidas coletivamente.

O segundo encontro foi uma oportunidade para os integrantes do grupo compartilharem um pouco de si, pois falar de si é muito difícil, ainda mais na frente de pessoas que não conheciam. Neste sentido, Boavida e Ponte (2002) enfatizam a importância do estabelecimento da confiança, pois, sem confiança, não há colaboração. 


\section{DOCENTE}

autêntica

Pensando no estabelecimento da confiança entre os integrantes do grupo, foi utilizada uma dinâmica a partir da música do cantor e compositores Almir Sater/Renato Teixeira: "Tocando em Frente." Depois disso, pudemos perceber, nos outros encontros, uma maior afinidade entre os professores, levando-os a compreender a importância das interações, para o processo de formação continuada, em especial, a participação no projeto OBEDUC.

No começo da pesquisa, a ideia era olhar para as interações e as reflexões de todo o grupo. Porém, no decorrer da pesquisa, optamos por analisar apenas as interações e as reflexões de um professor com o grupo e o subgrupo, sem deixar de levar em conta a importância que o grupo teve na sua constituição dentro do projeto e nos movimentos reflexivos.

No ano de 2014, uma escola municipal serviu como base para a aplicação das atividades desenvolvidas pelo subgrupo de forma colaborativa - local onde o professor da Educação Básica lecionava. As atividades abordaram o conteúdo de fração, mais especificamente, a noção de fração como parte de um todo, voltado para o sexto ano, e foram desenvolvidas em duas turmas.

No decorrer da pesquisa, o professor afirmou que a reflexão deve acontecer diariamente e é um aspecto essencial à sua atividade docente, embora ela não seja uma prática recorrente na sua formação inicial e nem mesmo nas formações continuadas. Mas, reconheceu que a experiência de refletir estava sendo estimulada até pelas conversas informais dele com os integrantes do Núcleo UFMS, durante a sua passagem pelo Projeto OBEDUC. No entanto, o professor considera que a sua experiência, embora importante, é escassa. Reconheceu que a reflexão não acontece facilmente no ambiente escolar.

Professor: [...] percebo um grave erro, que nós cometemos que é refletir sobre tudo o que foi feito em nosso trabalho, apenas no fim do ano letivo. [...] Em nosso trabalho, a reflexão deve acontecer todos os dias, é claro que isso não é uma tarefa fácil, somos humanos, temos uma vida. Porém, é necessário! Pois, o que podemos fazer no final do ano, se não conseguimos ensinar tudo o que era preciso? O tempo passou, o ano letivo acabou e já não se pode fazer mais nada pelos alunos, a não ser no próximo ano. (sic)

Concordamos com o professor sobre a importância da reflexão diária na sala de aula. Contudo, segundo Ibiapina (2008, p. 18), o "processo reflexivo exige mergulho tanto no conhecimento teórico quanto no mundo da experiência, para que se possa desvelar a que interesses servem as ações sociais e como elas reproduzem práticas ideológicas".

Chamamos a atenção para a fala do Professor ao enfatizar o quanto o projeto OBEDUC do Núcleo UFMS modificou o espaço de formação e tem proporcionado o compartilhamento de experiências e a valorização do professor da Educação Básica.

Professor: uma das coisas que me fez ter muita vontade de trabalhar na escola [...] é ela ser a última colocada no Ensino em termos de aprovação, índice do Ideb é a ultima. Então, quando teve a primeira reunião com os diretores e professores, eles pediram encarecidamente que nós, professores, falássemos o que nós poderíamos fazer durante o ano, para mudar a situação da escola. Então, eu vi aí a oportunidade de falar do nosso trabalho. Quando eu falei do nosso trabalho para o supervisor, ele ficou simplesmente maravilhado. E ele disse que é exatamente isso que a escola precisa, de professores com uma visão, não de quatro paredes! Que o pessoal, só fica em sala de aula. E a gente tem esse trabalho aqui, que ouve todo mundo e cada um tem opinião, essa troca de 


\section{autêntica}

informação faz com que tenhamos uma visão mais para fora da sala de aula, e ele está maravilhado. Na última reunião que fizeram com os professores, ele citou até o nome do nosso trabalho e ainda eu nem levei nada. Citou dizendo que essa seria uma das grandes formas de mudar a situação da escola. Então, o supervisor e o diretor estão dando toda abertura e condições para trabalhar lá na escola. (sic) (grifo do autor)

Um acontecimento interessante, no decorrer das atividades, foi a mudança na forma de avaliação do professor.

Professor: Eu não sei se estou empolgado demais, sabe? Para você ter uma ideia, eu decidi fazer uma prova prática, uma coisa que eu nunca fiz. Entendeu? Vou pegar o Tangram que eu achei bem legal, sabe? (sic)

A empolgação do professor, proveniente da aplicação das atividades, motivou-o ao ponto de levá-lo a mudar a forma de avaliação escolar. O uso da expressão "prova prática" também é algo revelador sobre como ele entendeu as atividades a respeito de frações. Por meio dessa expressão, foi possível inferir que o professor compreendeu-as como uma forma prática, uma forma manipulável de trabalhar os conceitos abstratos da Matemática. Para Zeichner (2008), os professores precisam saber como seus alunos aprendem para explicar determinados conceitos, "conduzir discussões, como avaliar a aprendizagem discente, conduzir uma sala e muitas outras coisas" (ZEICHNER, 2008, p. 546). Essa vivência do professor está relacionada à reflexão docente, pois o professor que tem conhecimento do conteúdo da disciplina e do conhecimento pedagógico que eles precisam ensinar reflete para mudar o processo de ensino e aprendizagem. Nesse caso, só precisam rejeitar "os modelos transmissivos de ensino que meramente promovem memorização" (ZEICHNER, 2008, p. 546).

Após as discussões de textos e também sobre a preparação e a aplicação das atividades, o professor foi questionado sobre o seu entendimento do que é ser um professor reflexivo.

Professor: [...] quando a gente coloca em prática esse tipo de trabalho que estamos fazendo, você vê o resultado ali na hora, [...] na participação dos alunos, na empolgação dos alunos e no aprendizado. Quando você faz simplesmente o básico, que é chegar lá e passar o conteúdo que está no livro, o resultado só vem depois, após a correção das provas. Sabemos que o correto é a avaliação contínua. [...] Quando você faz esse tipo de trabalho - planeja, aplica, pensa no que foi feito, no resultado que obteve, aplica novamente, e discute - isso se torna uma avaliação contínua. Então, eu acredito que isso seja o professor reflexivo. Você aplica o trabalho, o conteúdo, você volta, você pensa, reavalia, quando você avalia os alunos, você avalia o que você fez, aquilo que você ensinou, a maneira que você expôs o conteúdo, ai você dá continuidade ou muda, aborda de outra forma ou outra estratégia. Eu creio que seria isso. Não usei palavras teóricas, mas falei o que penso. (sic)

O professor entende como 'professor reflexivo' como aquele que está em constante atenção acerca do que acontece na sala, avaliando os resultados da aprendizagem dos alunos diante da forma escolhida para abordar tal assunto.

Ao final da pesquisa, concluiu-se que os ciclos de estudos colaborativos proporcionaram ao professor importantes movimentos de reflexão acerca da sua prática, pois favoreceram as interações, os diálogos e as negociações dos desafios vividos por ele em sala de aula.

As análises da pesquisa de Jorge (2015) buscaram compreender as práticas docentes do professor por meio dos depoimentos, das ações e dos diálogos no subgrupo e dos indícios de reflexão do professor, pelos 


\section{DOCENTE}

autêntica

movimentos do caminhar metodológico da espiral reflexiva ampliada - planejamento, entrevista, sessão reflexiva, novo planejamento e nova entrevista. A espiral sistemática de reflexão proporcionou ao professor refletir sobre as suas ações docentes, bem como propiciar mudanças por meio dos significados e pela ressignificação ou pelos novos significados atribuídos à prática docente.

Como unidades temáticas, foram estabelecidos os conteúdos sugeridos pelo professor - função do $2^{\circ}$ grau, função exponencial e função logarítmica. As atividades foram iniciadas com o planejamento do conteúdo de função do $2^{\circ} \mathrm{grau}$, devido à necessidade do professor. Após o planejamento da aula, feito conjuntamente no grupo, a aula foi aplicada. No decorrer da aula, o professor observou que os alunos não estavam conseguindo resolver as questões.

Professor: Sempre, no início da aula, ao entregar as questões para serem resolvidas, começam as perguntas: É para fazer na folha ou no caderno? Tem que entregar? Bom! A partir daí, eles começaram a interpretar os problemas. A minha intenção inicial era que eles conseguissem resolver, ter um norte para conseguir, nem que errassem a conta. O problema não eram eles acertarem ou errarem. Queria que eles conseguissem tirar os dados dos problemas, porém isso não aconteceu. Tive que estar auxiliando, não resolvendo. Foram planejados quatro exercícios. Dos quatro, eles só não pediram ajuda em um deles, que era o mais direto e de múltipla escolha. Nos outros exercícios, sempre tive que explicar uma coisa ou outra, pois eles não sabiam, por exemplo, naquele que falava da empresa de fax e do lucro, eles não sabiam o que era lucro. Então, para começar, eu fui ao quadro explicar para eles o que era lucro. [...]

Diante das dificuldades dos alunos para resolver os exercícios matemáticos, o professor explicou o que significou, para ele, os alunos não saberem resolver, pois durante o planejamento, ele acreditou que os alunos resolveriam.

Professor: [...] Quando eles conseguiram com muita ajuda, no quadro montar o produto, eles erraram a distributiva. Achei que eles sabiam resolver aplicando a distributiva, depois, eu percebi que não sabiam.

Professor: (...) quanto à resolução dos exercícios, os alunos resolveram muito pouco. A aprendizagem não foi a esperada e os objetivos não foram alcançados. Esperava-se que eles, pelo menos, tirassem os dados do problema. Eles podiam errar a conta, mas era para retirar os dados. Isso nós não conseguimos que eles fizessem.

Podemos perceber que o professor reconhece, após a aplicação da aula, que os alunos não sabem interpretar os exercícios, porque ele não trabalha com exercícios contextualizados. Diante do ocorrido, o professor propôs mudanças quanto à sua prática docente.

Professor: Então, eu tenho que mudar, porque eu sou muito direto. Já vou falando para eles que a função é assim, é assim que resolve o gráfico - você vai fazer sete pontos para construir o gráfico e vai marcar o vértice. Então, passo uma lista com cinquenta funções, para que resolvam. Assim, sem exercícios de aplicação, tipo álgebra pura que nós vemos na faculdade. Aquela chatice toda. Eu faço igual o professor fazia na disciplina que eu odiava.

Podemos perceber por essa fala que o professor refletiu após o planejamento e aplicação da aula, pois reconheceu a necessidade de mudança, principalmente quando olha para as questões do ENEM e para o resultado das Olimpíadas de Matemática. 


\section{DOCENTE}

\section{autêntica}

Professor: Foi bom! Eu gostei mesmo não tendo alcançado os objetivos. Gostei, porque vi que eu preciso mudar algumas coisas, dar mais probleminhas para resolver, ensinar como resolve o problema. Então, vendo por esse lado, a parte boa é que eles não aprenderam nada, mas eu aprendi que eu tenho que mudar o meu jeito. Até porque você prepara o aluno hoje, para viver em sociedade e para saber o ENEM. O ENEM todo é baseado em resolver problemas. Não tem questões diretas, então eu consegui ver que eu preciso mudar. Preciso melhorar, pois eles fizeram a Olimpíada de Matemática, onde também é dado muito problema, e não se saíram bem. Até mudei as minhas avaliações, para ver se eles conseguem aprender a resolver problemas, porque o problema é tudo.

Por meio dessa fala do professor após a aplicação da aula, podemos inferir que ele refletiu e essa reflexão pode ser caracterizada como prática e crítica, de acordo com Liberali (1999).

Diante das atividades elaboradas durante o planejamento, observamos, pelas falas do professor, que ele reconhece que o grupo, por meio dos diálogos que desenvolve, provoca mudanças em sua prática docente.

Professor: Eu tenho 60 horas/aula, então, não tenho tempo para formular questões diferentes. Assim, a ajuda do grupo facilitou a minha vida, porque nós acabamos nos acomodando e ficando bitolado. Você faz um planejamento para entregar para o coordenador do jeito que ele quer, assim ele assina e te devolve. Na verdade, nem seguimos aquilo que foi apresentado direito. Agora, quando é feito com a colaboração, como foi feito no grupo é um pecado não aplicar.

Professor: O planejamento que fazemos aqui é diferente do que fazemos na rede estadual. Lá você lança, o coordenador aprova e fica tudo lindo. Mas, na verdade, nada é lindo. Esse planejamento é mais real, porque o que eu planejei, eu tentei realizar. Algumas coisas não deram certo, mas eu tentei executar do jeito que nós havíamos planejado.

A partir da necessidade dos alunos e do olhar do professor, foi elaborado um novo planejamento e uma nova aplicação, de forma a iniciar com os alunos a interpretação por meio de exercícios contextualizados com as informações matemáticas mais explícitas e, a partir daí, foi feita uma nova entrevista.

Ao final da pesquisa, concluiu-se que o professor ao participar do projeto OBEDUC no Núcleo UFMS e das etapas da espiral reflexiva ampliada, por meio das ações desenvolvidas, conseguiu refletir e possibilitou mudanças na sua prática docente. 


\section{autêntica}

\section{CONSIDERAÇÕES FINAIS}

O projeto de pesquisa em rede, vinculado ao Programa Observatório da Educação, aqui apresentado, destaca as contribuições para a formação de um grupo colaborativo, visto que todos integrantes sentem-se compromissados com o desenvolvimento do projeto e o ponto principal é que não há uma hierarquia.

Nessa vertente, o grupo de trabalho colaborativo do Núcleo UFMS foi constituído a partir de um movimento participativo, colaborativo e reflexivo, concebido como um espaço formativo, promovendo processos de desenvolvimento profissional docente, possibilitando aos professores explorar e questionar os seus próprios saberes e práticas, além de propiciar o enfrentamento e a superação das necessidades apresentadas no desenvolvimento de suas práticas docentes.

Pelos resultados alcançados nas duas pesquisas apresentadas, podemos perceber a relevância do projeto em rede OBEDUC, o qual se revelou como um caminho possível de aproximação da escola com a Universidade. No entanto, entendemos que esse caminho que não é definitivo, pois, a partir das nossas interações no grupo de trabalho colaborativo, compreendemos que esse caminhar não se findou.

Foram muitas as contribuições que se efetivaram, não apenas em nossa prática docente e pedagógica, mas também tivemos indícios que transformações aconteceram, não há como participar de um movimento colaborativo sem deixar um pouquinho de si e levar um pouquinho do outro, existe um emaranhado de fios, os quais se tocam, se cruzam, se perpassam, constituindo novas redes, novos pensamentos, novas decisões, novos sujeitos.

Assim, a partir desse emaranhado de sujeitos vivos, os resultados das produções evidenciaram que a ação conjunta entre pesquisadores e professores da Educação Básica possibilitaram a ampliação e a produção de conhecimentos no campo educacional, que serviram como base para subsidiar o desenvolvimento de práticas docentes voltadas para a Educação Matemática, visando às melhorias do ensino e da aprendizagem da Matemática, bem como à formação continuada dos partícipes.

1 Essas informações foram extraídas do site da Capes, disponível em: http://www.capes.gov.br/educacao-basica/observatorio-da-educacao, acessado em 16 de janeiro de 2014. 


\section{DOCENTE}

autêntica

\section{REFERÊNCIAS}

ALARCÃO, I. Professores reflexivos em uma escola reflexiva. São Paulo: Cortez, 2003.

BOAVIDA, A. M.; PONTE, J. P. Investigação Colaborativa: Potencialidades e Problemas. In GTI (Org). Reflectir e investigar sobre a prática profissional. Lisboa: APM, 2002, p. $43-55$.

DESGAGNÉ, S. O conceito de pesquisa colaborativa: a ideia de uma aproximação entre pesquisadores universitários e professores práticos. Revista Educação em Questão. Natal, v. 29, n. 15, mai/ago 2007, p. 7 - 32.

FERREIRA, A. C. Metacognição e desenvolvimento profissional de professores de matemática: uma experiência de trabalho colaborativo. Tese (Doutorado em Educação: Educação Matemática), FE-UNICAMP. Campinas/SP, 2003

FIORENTINI, D. Pesquisar Práticas Colaborativas ou Pesquisar Colaborativamente? In: BORBA, M. C.; ARAÚJO, J. L. (Orgs.). Pesquisa Qualitativa em Educação Matemática. 5 ed. Belo Horizonte: Autêntica, 2013a, p. 53-85.

Aprendizagem profissional e participação em comunidades investigativas. Anais do XI ENCONTRO NACIONAL DE EDUCAÇÃO MATEMÁTICA. Curitiba, Paraná. 2013b.

Quando Acadêmicos da Universidade e Professores da Escola Básica Constituem uma Comunidade de Prática Reflexiva e Investigativa. In: FIORENTINI, D.; GRANDO, R. C.; MISKULIN, R. G. S. Práticas de Formação e Pesquisas de Professores que Ensinam Matemática. Campinas: Mercado das Letras, 2009, p. 223-256.

A pesquisa e as práticas de formação de professores de matemática em face das políticas públicas no Brasil. Bolema. (UNESP. Rio Claro. Impresso), v. 21, 2008, p. 43-70.

GATTI, B. A. Formação Continuada de professores: a questão Psicossocial. Cadernos de Pesquisa, n. 119, julho 2003, p. 191-204.

IBIAPINA, I. M. L. M. Pesquisa colaborativa: investigação, formação e produção de conhecimentos. Brasília DF: Líber Livro Editora, 2008.

JORGE, N. M. Reflexões sobre a prática docente de um professor de matemática a partir da pesquisa colaborativa. Dissertação (Mestrado em Educação Matemática). UFMS, 2015. 179p.

LIBERALI. F. C. O diário com ferramenta para a reflexão crítica. 166 f. Tese (Doutorado) - Pontifícia Universidade Católica de São Paulo. 1999.

MAGALHÃES, M. C. C.; OLIVEIRA, W. A colaboração crítica como uma categoria de análise da atividade docente. In: MAGALHÃES, M. C. C.; FIDALGO, S. S. (Orgs.) Questões de método e de linguagem na formação docente. Campinas, SP: Mercado de Letras, 2011.

NÓVOA, A. Formação de professores e profissão docente. In: NÓVOA, António (org.). Os professores e a sua formação. 2. ed. Lisboa: Dom Quixote, 1995, p. 13-33. 
PARDIM, J. F. S. Reflexões e interações de um professor da educação básica em um projeto colaborativo. Dissertação (Mestrado em Educação Matemática). UFMS, 2015. 77p.

PONTE, J. P. Perspectivas de desenvolvimento profissional de professores de Matemática. In J. P. Ponte, C. Monteiro, M. Maia, L. Serrazina, \& C. Loureiro (Eds.), Desenvolvimento profissional de professores de Matemática: Que formação? Lisboa: SPCE, 1995, p. 193 - 211.

SOUSA, M. C. Parcerias Compartilhadas entre Universidades e Escolas na Formação de Professores. Anais do XI Encontro Nacional de Educação Matemática. Curitiba, Paraná. 2013.

ZEICHNER, K. Repensando as conexões entre a formação na universidade e as experiências de campo na formação de professores em faculdades e universidade. Educação, v. 35, n. 3, maio/ago, 2010, p. 479-504.

Uma análise crítica sobre a "reflexão" como conceito estruturante na formação docente. Educ. Soc., Campinas, vol. 29, n. 103, maio/ago. 2008, p. 535-554.

A formação reflexiva de professores: ideias e práticas. Lisboa: Educa, 1993. 